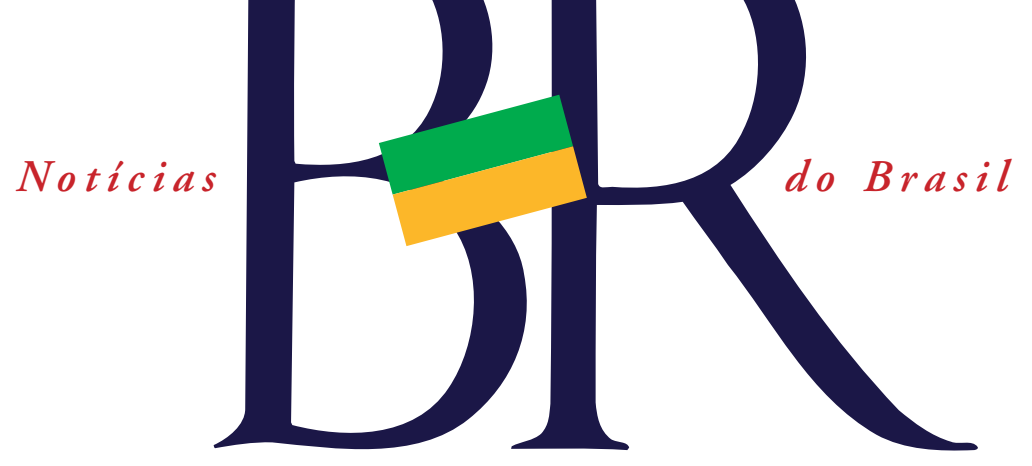

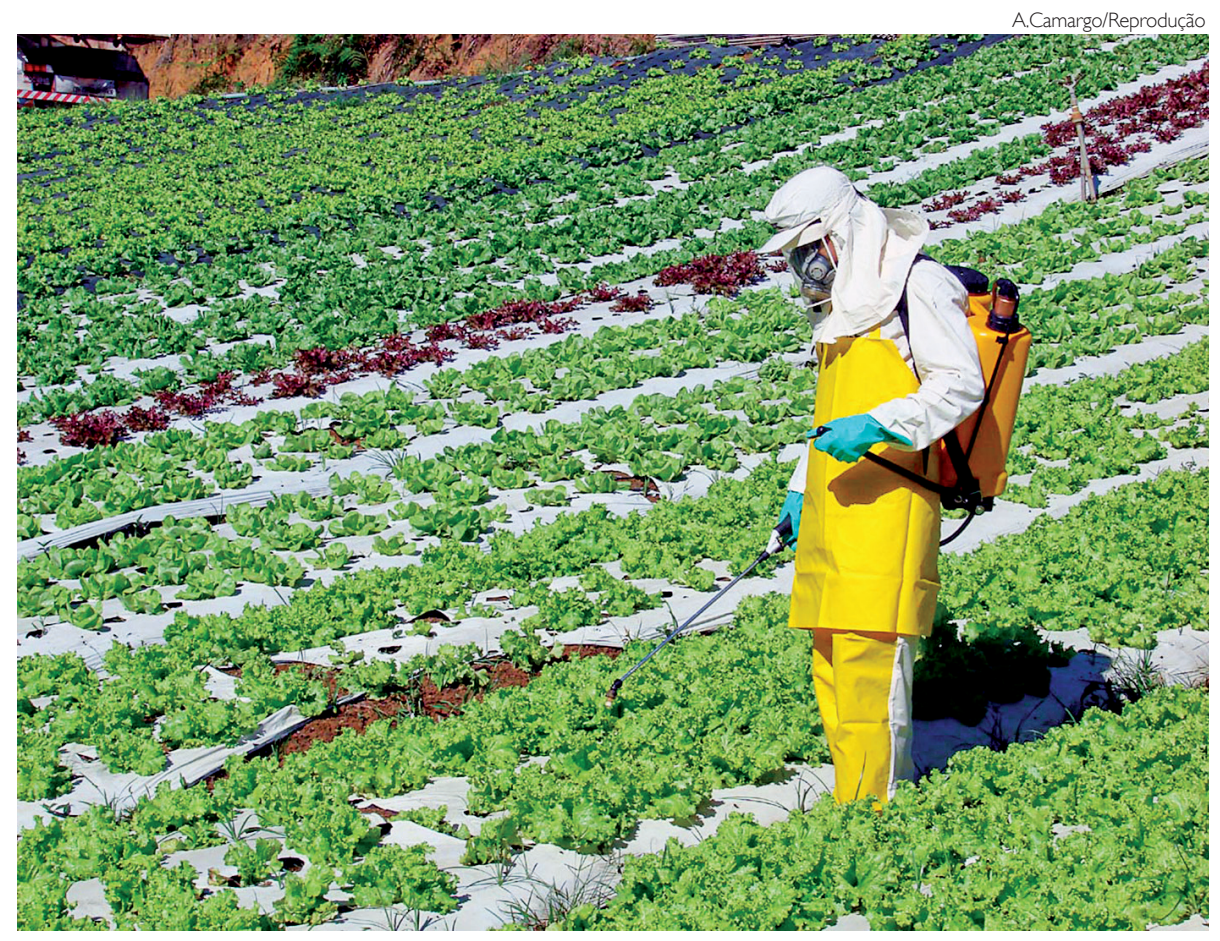

Mercado multibilionário dos insumos agrícolas recebe incentivo do governo federal

Agrotóxicos

\section{Agricultura brasileira é a maior consumidora mundial; gasto em 2011 chegou a R\$ 14 bilhões}

Na contracorrente dos países desenvolvidos, onde há forte tendência de redução no uso de agrotóxicos por conta dos danos diretos à saúde humana e impactos ambientais preocupantes, a agricultura brasileira ostenta números nada admiráveis: em 2011, as vendas de agrotóxicos no país alcançaram cerca de $\mathrm{R} \$ 14$ bilhões, um aumento de mais de $72 \%$ entre 2006 e 2012, e o consumo médio por hectare saiu de 7 para 10,1 quilos, num salto de 43,2\%. Desde 2008, o Brasil ocupa a primeira posição no consumo mundial, quando ultrapassou os Estados Unidos. Atualmente, é responsável pelo consumo de 1/5 dos agrotóxicos produzidos no mundo e, entre 2000 e 2010, enquanto o mercado mundial de tais produtos subiu $93 \%$, o mercado brasileiro cresceu 190\%. Comemorando, certamente estão as 130 empresas produtoras de defensivos agrícolas que atuam no país.
Os defensores do uso de agrotóxicos alegam que o consumo no país é alto porque a área plantada é muito extensa. Segundo a Companhia Nacional de Abastecimento (Conab), na safra 2011/2012, a área cultivada com grãos, fibras, café e cana-de-açúcar foi de 81,7 milhões dehectares. Outroargumentoéque, nos últimos 20 anos, a safra de grãos tem batido recordes sucessivos de produtividade. A produção de soja, por exemplo, saltou de 15,4 milhões de toneladas na safra 1980/1981 para 75,3 milhôes de toneladas na safra 2010/2011, ganho atribuído em parte ao combate sistemático de pragas e doenças. Argumenta-se, ainda, que o Brasil tem clima tropical, o que favorece a proliferação de ervas daninhas, fungos, insetos, bactérias e vírus.

Àsociedadefica o papel deavaliarseo preço pago pela população brasileira não seria alto demais para justificar um modelo que consome recursos na forma de isenção de impostos e sobrecarrega a saúde pública. Os que preconizam o uso de agrotóxicos procuram difundir o uso correto e seguro desses produtos. O desafio é garantir uso seguro de venenos agrícolas num país continental, onde é possível comprar o produto que estiver disponível e usá-lo sem que haja monitoramento dos efeitos no ambiente e na saúde de trabalhadores e consumidores. Além disso, nenhum estudo laboratorial pode 
assegurar que determinado nível de veneno é inócuo, pois, entre outros fatores, depende do estado de saúde do indivíduo que vai manipulá-lo. Existem técnicas alternativas para combater pragas, doenças e plantas infestantes nas lavouras, mas são ainda pouco praticadas em larga escala. O uso intensivo de agrotóxicos tem menos de 70 anos, certamente aumentou a produtividade agrícola, mas não melhorou a segurança e a soberania alimentar da humanidade. Ao contrário: hoje quase um bilhão de pessoas são desnutridas ou subnutridas no planeta.

Porém, enquanto políticas públicas para o setor agrícola privilegiarem sistemas de produção intensivos, com monoculturas em grandes extensôes de terra, visando à exportação de produtos com baixo valor agregado, os agrotóxicos serão cada vez mais necessários para combater o que não pode ser combatido por meio da biodiversidade perdida. Outro desafio a enfrentar é de ordem cultural: enquanto o consumidor preferir um produto com aparência perfeita, os alimentos oferecidos por sistemas de produção agroecológicos não ganharão escala e continuarão mais caros.

CONTAMINAÇÃo dA ÁGUA, ALIMENTO E LEITE MATERnO O Dossiê Abrasco: Um alerta sobre os impactos dos agrotóxicos na saúde - Parte 1: Agrotóxicos, segurança alimentar esaúde, elaborado pela Associação Brasileira de Saúde Coletiva (Abrasco), discute a escalada crescente de uso de agrotóxicos no país e de contaminação do ambiente e das pessoas. Com base em análises de amostras coletadas em todos os 26 estados, realizadas pelo Programa de Análise de Resíduos de Agrotóxicos em Alimentos (Para) da Anvisa, o dossiê aponta que um terço dos alimentos consumidos cotidianamente pelos brasileiros está contaminado por agrotóxicos. E acrescenta: mesmo que alguns dos ingredientes ativos possam ser classificados como medianamente ou pouco tóxicos, com base em seus efeitos agudos, é necessário considerar os efeitos crônicos que podem ocorrer meses, anos ou até décadas após a exposição, manifestando-se em várias doenças como cânceres, malformação congênita e distúrbios endócrinos, neurológicos e mentais. Raquel Rigotto, professora do Departamento de Saúde Comunitária da Faculdade de Medicina da Universidade Federal do Ceará (UFC), que participou da elaboração do documento da Abrasco, destaca ainda que um problema no controle é que não se considera a soma dos ingredientes consumidos. Nas muitas misturas feitas, existem inúmeras combinações possíveis; pode haver antagonismo entre ingredientes o que potencializaria os efeitos na saúde humana e no ambiente. Além disso, pouco se sabe sobre os efeitos dos metabólitos, produzidos a partir da degradação do produto originalmente aplicado, e sobre o tempo de permanência dessas substâncias no ambiente, acrescenta Raquel.

O Atlas de Saneamento de 2011, elaborado pelo Instituto Brasileiro de Geografia Estatística (IBGE), aponta que esgoto sanitário, resíduos de agrotóxicos e destinação inadequada de lixo foram responsáveis por $72 \%$ das incidências de poluição na captação em mananciais superficiais, $54 \%$ em poços profundos e $60 \%$ em poços rasos, considerando os municípios que declararam poluição ou contaminaçãa. E um aspecto inquietante é que ao longo dos anos constata-se um aumento dos tipos de substâncias cuja presença nas águas é permitida: de 1977 para 2011, a presença de agrotóxicos aumentou de 12 para 27 tipos.

E os casos de contaminação se multiplicam país afora. Estudo conduzido por pesquisadores da Universidade Federal do Mato Grosso (UFMT), de 2007 a 2010, após a chuva de agrotóxicos que atingiu a zona urbana de Lucas do Rio Verde (MT) em 2006, por uso do herbicida paraquat em pulverização aérea no entorno da cidade, apontou que a exposição da população local (pelo ambiente, no trabalho ou por alimento) foi de 136 litros de agrotóxicos por habitante por ano. Dos 12 poços de água potável analisados, $83 \%$ estavam contaminados com resíduos de vários tipos 


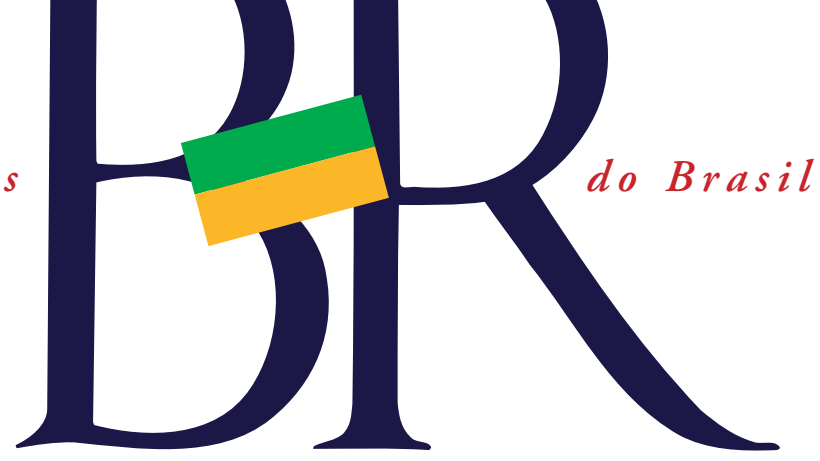

de agrotóxicos, assim como mais da metade das amostras de água da chuva. E mais: a análise do leite materno de 62 mulheres apontou que todas tinham presença de, pelo menos, um tipo de agrotóxico.

O relatório da Subcomissão sobre o Uso de Agrotóxicos e suas Consequências à Saúde, aprovado em dezembro de 2011 pela Comissão de Seguridade Social e Família da Câmara dos Deputados, apontou correlação entre o aumento da incidência de câncer e o uso de agrotóxicos na agricultura. Um dos exemplos citados é o da cidade de Unaí (MG), onde foram registrados 1.260 novos casos de câncer por ano em cada 100 mil habitantes. No mundo essa taxa é de 600 casos.

Nos últimos anos, o Brasil se tornou o principal destino de produtos banidos no exterior. Em 2008, em função de alertas sobre o perigo para a saúde humana, a Agência Nacional de Vigilância Sanitária (Anvisa) colocou em reavaliação 14 ingredientes ativos de agrotóxicos. Entretanto, já em 2008, decisões judiciais impediram, por quase um ano, que isso se concretizasse. Atualmente, cinco dos 14 ingredientes já tiveram seus processos concluídos. Mas ainda são usados nas lavouras brasileiras pelo menos nove produtos proscritos na União Europeia, Estados Unidos, China e outros países.

\section{INCENTIVOS FISCAIS NO BRASIL}

O uso de agrotóxicos na agricultura teve seu primeiro grande incentivo em 1965 por meio do Sistema Nacional de Crédito Rural, que vinculava o crédito agrícola à obrigatoriedade de compra de insumos químicos pelos agricultores. Em 1975, o Programa Nacional de Defensivos Agrícolas destinou recursos financeiros para a criação de empresas de insumos agrícolas. Mas são as isenções fiscais e tributárias concedidas ao comércio desses produtos que, até hoje, impulsionam esse mercado multibilionário. Desde 1997, encontra-se vigente o Convênio ICMS 100/97, segundo o qual o governo federal concede redução de $60 \%$ da alíquota de cobrança do ICMS (Imposto sobre Circulação de Mercadorias e Serviços) a todos os agrotóxicos.

Flavia Londres, em seu livro Agrotóxicos no Brasil: um guia para ação em defesa da vida, assinala que o Decreto 6.006/06 isenta completamente da cobrança de IPI (Imposto sobre Produtos Industrializados) agrotóxicos fabricados a partir de uma lista de dezenas de ingredientes ativos, dentre eles o glifosato, campeão de vendas, e o metamidofós, retirado de mercado em junho de 2012 pela Anvisa. Além disso, o Decreto 5.630/05 isenta da cobrança de PIS/Pasep (Programa de Integração Social/Programa de Formação do Patrimônio do Servidor) e de Cofins (Contribuição para o Financiamento da Seguridade Social) os defensivos agropecuários classificados na posição 38.08 da NCM (Nomenclatura Comum do Mercosul) e suas matérias-primas, que compreende produtos diversos das indústrias químicas como inseticidas, fungicidas e herbicidas. Além das isenções federais, há as isenções complementares determinadas por alguns estados. No Ceará, por exemplo, a isenção de impostos para atividades envolvendo agrotóxicos chega a 100\%, afirma Flavia.

No Brasil, a venda de agrotóxicos é controlada; o comprador deve apresentar um receituário agronômico assinado por engenheiro agrônomo, após vistoria da lavoura. Na prática, a situação é bem diferente. A professora Raquel Rigotto explica que "a maioria das revendas conta com um agrônomo que passa de vez em quando, às vezes uma vez por mês, para assinar receituários agronômicos". Ou seja, o agricultor não recebe a devida orientação e muitas vezes a compra não é a mais adequada para as suas reais necessidades. 